\title{
Markers of pancreatic cancer stem cells and their clinical and therapeutic implications
}

\author{
Arkadiusz Gzil $^{1}$ (D ) Izabela Zarębska ${ }^{1} \cdot$ Wiktor Bursiewicz $^{1} \cdot$ Paulina Antosik $^{1} \cdot$ Dariusz Grzanka $^{1} \cdot$ Łukasz Szylberg $^{1,2}$
}

Received: 6 March 2019 / Accepted: 31 August 2019 / Published online: 5 September 2019

(c) The Author(s) 2019

\begin{abstract}
Pancreatic cancer (PC) is the fourth most common cause of death among all cancers. Poor prognosis of PC may be caused by a prevalence of cancer stem cells (CSCs). CSCs are a population of cancer cells showing stem cell-like characteristics. CSCs have the ability to self-renew and may initiate tumorigenesis. PC CSCs express markers such as CD133, CD24, CD44, DCLK1, CXCR4, ESA, Oct4 and ABCB1. There is a wide complexity of interaction and relationships between CSC markers in PC. These markers are negative prognostic factors and are connected with tumor recurrence and clinical progression. Additionally, PC CSCs are resistant to treatment with gemcitabine. Thus, most current therapies for PC are ineffective. Numerous studies have shown, that targeting of these proteins may increase both disease-free and overall survival in PC.
\end{abstract}

Keywords Pancreatic cancer · Cancer stem cells · Prognostic factors

\section{Introduction}

The diagnosis and treatment of pancreatic cancer (PC), which is the fourth most common cause of death among all cancers, is a current and important medical problem. The low survival rate for $\mathrm{PC}$ has been confirmed by data from 185 countries analyzed in the GLOBOCAN study of 2018, which clearly showed that the number of new cases of PC was similar to the number of deaths $(458,918$ vs. 432,242$)$ [1]. According to the WHO, the most common type of PC is adenocarcinoma [2]. The main factor contributing to such a low survival rate is the diagnosis of PC in its advanced stages (52\% for advanced stages vs. $9 \%$ for the initial stages) for whom the 5 -year-survival rate is only $2-5 \%$. The cancer mortality is caused predominantly by dysfunction of organs due to metastasis. This process is related to epithelial-mesenchymal transition (EMT), which is the transformation of cells from the epithelial to the mesenchymal-like phenotype.

Arkadiusz Gzil

arkadiuszgzilresearch@gmail.com

1 Department of Clinical Pathomorphology, Collegium Medicum in Bydgoszcz, Nicolaus Copernicus University in Torun, Sklodowskiej-Curie Str. 9, 85-094 Bydgoszcz, Poland

2 Department of Pathomorphology, Military Clinical Hospital, Bydgoszcz, Poland
Cells which undergo EMT have increased motility, are more invasive, and are resistant to apoptosis [3]. The most important contributory factors in PC are smoking (strong correlation) and the presence of Helicobacter pylori infection (moderate correlation), although diet and type 2 diabetes also play an important role [4, 5]. In addition, a recent study emphasized the role of chronic ethanol consumption on the transformation of normal human pancreatic ductal epithelial cells into altered cells with cancer stem cell phenotypes (CSCs) [6].

CSCs are a specific population of cancer cells showing stem-cell like characteristics and, according to increasing evidence, they may initiate the development of PC as is the case with other neoplasms [7] [8] [9]. CSCs seem to generate daughter cells through the process of cell division, which may occur next to ordinary tumor cells representing the major component of the tumor, or self-renew, maintaining the full ability to differentiate and divide just as the parent stem cell does [10] [11]. The possibility of detecting specific markers identifying PC CSCs was investigated. There are several specific proteins that belong to this group, including CD133, CD24, CD44, CXCR4, EpCAM, Oct4, ABCB1, ABCG2, c-Met, ALDH-1, and nestin [12] [13] [14]. A unique feature of CSCs is their resistance to drugs. Without the elimination of this subpopulation during chemoor radiotherapy of $\mathrm{PC}$, it may induce tumor recurrence and subsequent clinical progression [15]. This may be one of 
the reasons for the unsatisfactory outcomes in the cases of PC treatment [16].

Five-year-survival accounts for no more than $32 \%$, even among patients who are diagnosed during the early stages of this disease. The classical approach to treatment is gemcitabine-based chemotherapy as the first line option, however this approach shows only limited benefit on the overall survival rate of patients with locally advanced or metastatic PC [16] [17]. Currently, monotherapy with gemcitabine is recommended as an adjuvant treatment, in locally advanced cancer for 6 months, and as a palliative procedure among patients with ECOG (Eastern Cooperative Oncology Group) [18] performance scores of 2 and/or bilirubin levels higher than $1.5 \times$ ULN [19]. Fluorouracil (5-FU) with folinic acid, is another method used in addition to surgery [19]. To improve the outcome in cases of advanced PC, new cycles of chemotherapy were investigated in individuals with this disease, which led to new regimens in clinical practice, such as FOLFIRINOX (Leucovorin + Fluorouracil + Irinotecan + Oxaliplatin) or nab-paclitaxel plus gemcitabine [20] [21] [22]. However, these regimens are recommended for palliative care, in cases of metastatic disease, only for patients with ECOG performance status scores of 0 or 1 and a bilirubin level below $1.5 \times$ ULN, because of the increased toxic side effects [19]. Nonetheless, the effectiveness of the new treatments remain limited.

The aim of this review was to summarize the most current and available information about the diverse subpopulation of CSCs in cases of PC, strictly in connection with their influence on the clinical features of the disease, prognostic features of specific CSC markers, and with the challenges related to the treatment process and behavior of these cells. Another aim was to collect data about the future possibility of targeting CSC markers in order to increase the efficacy of chemotherapy in PC.

\section{Markers of cancer stem cells in pancreatic cancer as independent prognostic factors}

\section{CD24}

CD24 is a small mucin-like glycosyl phosphatidylinositol (GPI)- linked cell surface protein involved in cell adhesion. It is present in the developing brain and kidneys [23, 24]. CD24 seems to be involved in the development of PC. Jacob et al. revealed diminished or absent expression of CD24 in normal pancreatic tissue and noticeable cytoplasmatic levels in PanIN (pancreatic intraepithelial neoplasia). Increasing expression of CD24 was observed in cells during the progression from normal ductal epithelium to invasive intraductal papillary mucinous carcinoma. Expression levels increased in line with increasing grade of atypia in intraductal papillary mucinous neoplasms. Smith et al. showed that CD24 expression is regulated by Ral GTPases. The Ral family initiates transcription through TCF downstream pathways and activation of transcription factors, such as Jun, NF- $\mathrm{kB}$ and AFX, which regulate the expression of CD24 [25] [26]. Moreover, Moghadam et al. observed more intensive oncogenic activity of the Ras-related protein Ral-A (RalA) in CD24+ cancer cells in comparison to CD24- cancer cells. Overexpression and increased RalA activity is predominant in $\mathrm{PC}$ and it is associated with tumorigenic growth [27] [28]. CD24 also seems to be involved in integrin-associated cell to matrix adhesion and regulation of cellular morphology through stress fibers, processes of rounding, and nuclear condensation, and therefore protects cancer cells from apoptosis [25]. In primary PC, CD24 was overexpressed in high-grade tumors and more advanced PC stages, suggesting its role in the progression of PC. According to Ikenaga et al. higher tumor stage, nodal metastasis, higher-grade tumors, microscopic lymphatic and venous and neural invasion was more frequently observed in their CD24+group than in the group with CD24-negative PC. The shorter survival period was also associated with higher levels of CD24 expression, 12 months in the group with strong expressions, 19 in those with weak expression, and 23 in those with none $[29,30]$.

\section{CD133}

CD133 is a transmembrane protein that is found in lipid rafts, with a ganglioside-binding extracellular domain and a cytoplasmic domain, with the capability of tyrosine phosphorylation [31-34]. The process of CD133 transcription is regulated by five promoters (P1, P2, P3, P4 and P5) [35]. According many studies $\mathrm{P} 5$ seems to play crucial role by CD133 expression in PC CSCs. Its activation could be performed by a downstream signaling pathway initiated by one of the extracellular signal-regulated kinases (ERKs), mainly by ERK1 or ERK2 [35]. In CSCs of PC ERKs are inducted by MAPK/ERK pathway triggered through the TrkA receptor in response to auto- or paracrine secreted Nerve growth factor (NGF) [36-39]. On the other hand P5 appears to be a target for heat shock proteins such as HIF- $1 \alpha$ and HIF-2 $\alpha$ [35].Their expression increases during carcinogenesis in pancreatic tissue due to oxygen deficiency in the PC region, leading to increased CD133 transcription [40-42]. Other studies showed that $\mathrm{Wnt} / \beta$-catenin signaling has been closely associated with regulating PC development and has promoted the self-renewal of CD133+ cancer cells [43-45]. Moreover, a study by Nagathihalli et al. showed that inhibition of Janus kinases (JAK) or Signal Transducer and Activator of Transcription protein 3 (STAT3) cause downregulation of CD133 + [39]. Recent studies have revealed significantly lower expression of CD133 in 
normal pancreatic tissue (in under $0.01 \%$ of cancer cells) in regards to PC [46] [38]. PCs are characterized by populations of $0.5-1 \%$ of CD133+ cells in less aggressive cell lines to more than $9 \%$ of CD133+ cells in clones with increased rates of migration [47]. CD133 is a substrate for Src-family tyrosine kinases such as the proto-oncogene tyrosine-protein kinases Src and Fyn, which phosphorylate its cytoplasmic domain at tyrosine-828 and tyrosine-852 [31, 48].The result of this is the triggering of downstream regulatory signals for stemness properties (such as enhanced telomerase reverse transcriptase expression, increased Akt phosphorylation and ligand-independent EGFR activation) and EMT [49]. EMT has been reported to be regulated in PC by the NF- $\mathrm{KB}$ signaling pathway, which is activated by CD133 [50] [51]. The overexpression of CD133 increases the expression and secretion of IL1 $\beta$ (IL1B) by CSCs, activating an autocrine signaling loop that upregulates NF- $\mathrm{KB}$ signaling in cancer cells [52]. Studies have suggested that CD133 expression is significantly associated with metastases to the lymph nodes, clinical TNM stage and tumor differentiation in patients with PC [53] [54]. Moreover, high CD133 expression has been described as an independent prognostic factor for lower disease-free survival [46]. On the other hand, Durko et al. concluded that there was no significant influence of CD133 expression on overall patient survival [55].

\section{DCLK1}

The microtubule regulator DCLK1 marks a subpopulation of morphologically and functionally distinct pancreatic cells identified at the earliest stages of pancreatic tumorigenesis, which could function as CSC [56-58]. The upstream regulators of DCLK1 have not yet been satisfactorily investigated. The upregulation of DCLK1 could be promoted by the overexpression of immune cell-derived IL17 which is produced by mesenchymal inflammatory cells, increasing DCLK1 expression through activation of nuclear factor $\mathrm{kB}(\mathrm{NF}-\mathrm{kB})$ via the canonical pathway to promote stemness [59]. Overexpression of DCLK1 is responsible for the regulation of many intracellular pathways during malignant transformation of pancreatic tissue, mostly due to microRNA-related mechanisms [60-62]. It promotes tumorigenesis through the upregulation of important drivers of pancreatic tumorigenesis, such as cMyc and KRAS through a let-7a microRNA(let-7a)-dependent mechanism [62-64]. KRAS is mutated in more than $95 \%$ of all PC cases $[65,66]$. The increasing level of DCLK1 cells could be an early event in KRAS-induced pancreatic tumorigenesis and its overexpression is significant related with presence of activated mutant Kras in PC tissues [58, 62, 67]. Another commonly overexpressed PC oncogene is epidermal growth factor receptor (EGFR) [68]. According to the findings of Sureban et al. DCLK1 may upregulated by EGF signaling [61]. It was reported that miR-145 and miR-143 inhibit cell proliferation by targeting EGFR in various types of cancers, $[69,70]$ and through their suppression, dependent on DCLK1, cell cycle arrest could be overcome. The NOTCH pathway (especially Notch-1) is a target of suppressor MicroRNAs, such as the miR-200 family (ZEB1 and miR-200) and the miR-144 family, whose deregulation could be caused by DCLK and lead to increased proliferative signaling in PC [61, 62, 71]. DCLK1 is also associated with the pluripotency of PC due to the repression of other tumor suppression factors including miR-143, miR-145 and let-7a, resulting in overexpression of pluripotency agents such as OCT4, SOX2, KLF4, NANOG and LIN28B [61, 62, 72, 73]. It has also been reported that the influence of DCLK1 on apoptosis is due to the stimulation of 14-3-3 $\sigma$ expression, which is an inhibitor of pro-apoptotic activity in PC $[62,74$, 75]. DCLK1 induces deregulation of VEGF-inhibitors and leads to neovascularization of $\mathrm{PC}$ and, as a consequence, tumor growth [61, 76-81]. Clinically, the DCLK1+ expression correlates with the histological grade and preoperative CA19-9 level [82]. Furthermore, the overexpression of DCLK1 was observed in metastatic PCs, and the population of DCLK1+cells in metastatic tissues was larger than that of primary tumors [83]. DCLK1 may promote the metastatic capability of PC through its impact on EMT. One of the functions of the miR-200 family is the prevention of EMT in several cancers by inhibiting the transcription factors ZEB1 and ZEB2 [84, 85]. DCLK1 decreases the levels of these MicroRNAs and, in consequence, leads to the activation of processes by upregulation of EMT proteins such as Snail, Slug and Twist [61, 62]. The overexpression of DCLK1indirectly stimulates the oncogene $B M I 1$ with upregulation of the Polycomb complex protein Bmi-1 expression in PC, which leads to the triggering of EMT through upregulation of mesenchymal markers such as Snail and Vimentin, as well as by downregulation of the epithelial marker E-cadherin [86]. The study also found that DCLK1 is an unfavorable prognostic factor in $\mathrm{PC}$, with median overall survival after resection being 18.7 or 49.5 months in tumors with positive and negative DCLK1 expression respectively. Additionally, the median disease free survival time has been found to be shorter among PCs with DCLK1 expression (10.2 months) in comparison to PCs without DCLK1 surface expression (25.5 months) [82].

\section{CD44}

Another important marker is CD44. It is a membrane receptor for hyaluronic acid (HA), osteopontin, chondroitin, collagen, fibronectin and serglycin/sulphated proteoglycan. Therefore, CD44 is involved in processes such as cellular adhesion, angiogenesis, the release of cytokines and muscle repair [1] [2].There is evidence that this 
protein might have an important role in the development of PC cancer. The CD44 gene is encoded by 20 exons. The standard CD44 isoform (CD44s) is composed of exons 1-5 and 16-20, thus it is called the constant form. The variant CD44 isoform $(\mathrm{CD} 44 \mathrm{v})$ consists of the middle exons, which can be spliced and assembled with the ten exons present in CD44s. Therefore thousands of CD44 isoforms could possibly be generated [87-89]. In healthy cells p53 binds to a noncanonical p53-binding sequence of the CD44 promoter, which inhibits its expression. It has been shown that loss-of-function mutations of p53 may be associated with up-regulation of CD44, leading to the promotion of tumor growth [90]. The study of $\mathrm{Li}$ et al. showed increased CD44v and decreased CD44s expression in metastatic PC. Furthermore, CD44s and CD44v were found to be associated with metastases to the lymph nodes and liver. [1] [3]. Probably, the role of CD44v in invasion is associated with its interaction with the oncogenic transcription factor c-Myc. c-Myc activates the MEK and Erk pathways which leads to increased antiapoptotic activity due to decreased Fas signalling [91] [92]. Studies have shown that HA-CD44 binding also leads to upregulation of other transcription factors such as Nanog, Sox 2 and Oct4. This interaction promotes miR-302 and miR-21 overexpression resulting in increased spheroid and clone formation, as well as cell growth/self-renewal in CD44v ${ }^{\text {high }}$ cancer cells [93-96]. High invasiveness and the increased ability to metastasise of CD44+ PC is also associated with EMT. Overexpression of CD44 leads to an increase in EMT-related mesenchymal cancer cell phenotypes. What is more, switching between CD44v and CD44s is crucial in EMT and the CD44s isoform seems to be the most prevalent in EMT [87, 97, 98]. A study by Brown et al. showed that CD44s upregulation correlated with the levels of mesenchymal markers and high grade of cancer. The authors also observed that CD44s activated the Akt pathway inhibiting E-cadherin expression and thus introducing EMT. According to their evidence, epithelial cell-type-specific splicing regulator (ESRP1) is connected with this process. It stimulates CD44 posttranscriptional changes and is commonly expressed in epithelial cells. ESRP1 knockdown in CD44v cells was found to be associated with switching to CD44s and to the suppression of metastasis. ESRP1 overexpression prevented cells from undergoing EMT by stimulating CD44 splicing, which led to high levels of CD44v and blocked the switch from CD44v to CD44s [3] [99] [100]. There are clinical consequences of these alternations and several studies have demonstrated the correlation between CD44 expression and poor prognosis in PC. CD44 overexpression has been correlated with advanced clinical stage and lymph metastases [101]. Hong et al. revealed that median survival of patients with CD44 positive PC was shorter (20.3 months) than for patients with CD44 negative PC (25.3 months) [102].

\section{CXCR4}

CXCR4 is a G-protein-coupled receptor for stromal-derivedfactor-1 (SDF-1). CXCR4 expression occurs mainly on hematopoietic cells but its presence can be found on other cells such as endothelial cells, stromal cells or on the surface of mature blood cells [103, 104]. CXCR4 and SDF-1 are currently playing an increasingly important role in the pathogenesis of PC. In the work of Koshiba et al. CXCR4 expression was shown to be present in most cases [105-107]. The expression of CXCR4 is regulated in healthy cells by Nuclear Respiratory Factor 1 (NRF1) and Ying Yang 1. NRF1is a second messengers of many cellular signaling pathway and growth factors promote transcription of CXCR4 whereas Ying Yang 1 and proinflammatory factors have the opposite effect CXCR4, by joining CXC12, is involved in the migration of immune cells within the bone marrow and lymph nodes $[110,111]$. In the case of the neoplastic process, of $\mathrm{PC}$, a similar principle may lead to metastasis. Expression of CXCR4 on the surface of tumor cells can direct the tumor metastases towards SDF-1 expressing tissues via SDF-1-CXCR4 axis [112, 113]. Other studies have suggested the involvement of CXCR4 in metastases as a result of increased NK cell apoptosis. A number of mechanisms have been proposed in which CXCR4 interacts with the tumor microenvironment. Burger and Kipps have presented the influence of tissue hypoxia on the expression of CXCL12 by fibroblasts which directly activates CXCR 4 and, at the same time, stimulates the attraction of cancer cells that contain this receptor on their surface [114]. Maréchal et al. suggested a positive correlation between high CXCR4 expression and a shorter 5-year overall survival and a greater risk of lymph node and liver metastases [115]. One of the possible mechanisms by which CXCR4 may affect the development and progression of $\mathrm{PC}$ is its interaction with CXCL12, which may lead to increased angiogenesis and the formation of new blood and lymphatic vessels. In the study of Cui et al. a higher microlymphatic vessel density was found in patients with higher CXCR4 expression, but with no apparent effect on microvessel density, which was more dependent on higher CXCL12 expression [116].

\section{Oct4}

Oct 4 is a protein belonging to the POU family and is responsible for differentiation and pluripotency $[117,118]$. Oct4 is a transcription factor, whose gene is located on chromosome 6 (6p21.31). This protein is the main factor in pluripotency, participating in cell differentiation, reprogramming and renewal [119]. Oct4 fulfills its role by binding an octameric 
sequence motif (ATGCAAAT) which allows for the regulation of gene expression [120]. In the initial stage of development, this protein is present in all parent pluripotent cells whereas in later stages its expression can be demonstrated in germinal stem cells [121]. The highest expression of Oct4 occurs in undifferentiated cells and decreases as the cells are differentiated. Oct 4 , combining with other factors such as SOX2 and NANOG, participates not only in the regulation of gene expression responsible for cell renewal and differentiation but also affects the expression of other factors such as fibroblast growth factor 4 (FGF4) [122, 123]. Statistically significant increased expression of Oct 4 can be found in metaplastic ducts $(79.2 \%)$ compared to malignant (19.4\%) and nonmalignant (16.7\%) tissue and high Oct4 expression is correlated with tumor differentiation $[124,125]$. In order to explain the role of Oct4 in pancreatic tumors, Lu et al. knocked down both Oct4 and Nanog, which contributed to a reduction in proliferation, migration and invasion of $\mathrm{PC}$ stem cells and to increased sensitivity to chemotherapy with gemcitabine. The probable mechanism, as postulated by the authors, is based on the regulation of Caspase- 3 and Bcl-2 expression [126].

\section{ESA}

ESA (EpCAM) is a type I transmembrane glycoprotein expressed on most epithelia. A study by Maetzel et al. showed that EpCAM intracellular domains form a complex with $\beta$-catenin and LEF- 1 which activates the transcriptions of genes such as c-Myc and cyclins A and E. Its overexpression increased the phosphorylation of AKT, mTOR, p70S6K and 4EBP1 as well as decreased PTEN expression. EpCAM regulates EMT and metastasis in vivo [127] [128]. The study of Fong et al. revealed that ESA was overexpressed in PC and that it was related to shorter survival of patients with advanced PC. Patients with advanced PC and ESA overexpression had an overall survival period of 48 months, whereas without this marker, the period was more than 70 months [129].

\section{ABCB1}

ABCB 1 (MDR1 P-glycoprotein) is a member of the ABC superfamily of drug transporters, and is involved in the resistance of pancreatic cells due to increased drug efflux [130]. Histopathological studies indicate that $63 \%$ of pancreatic tumors express glycoprotein, which is related to multidrug resistance of these cancers [131]. $A B C B 1$ is a transcriptional targets of $\mathrm{WNT} / \beta$-catenin signaling and, in the case of gain-of-function CTNNB1 mutations, leads to overexpression of ABCB1 in PC [132]. Moreover, transcription of $\mathrm{ABCB} 1$ is also increased by the activation of cells by leptins in the PC microenvironment [133]. It has been reported that
microRNA-21, detected in PC tissue, promotes upregulation of ABCB1 in cancer cells [134-136]. ABCB1 expression is directly activated by the demethylation of $\mathrm{CpG}$ islands in the ABCB1/MDR1 promoter region [137]. Patients with high $\mathrm{ABCB} 1$ immunostaining had a shorter postoperative survival time (7.5 months) when compared with patients with weak to moderate expression of this protein [138].

\section{Co-expression of CSC markers in pancreatic cancer}

The co-expression of several of the above-mentioned CSC markers was also investigated in the clinical context. There is more and more evidence that emphasizes the role of the triplet CD24, CD44, ESA in PC. The expression patterns of these proteins could be associated with the microenvironment of PC [139]. Furthermore, a study by Li et al. revealed a correlation between a subset of CD24+CD44+ESA+ CSCs, with the capability of self-renewal and with up-regulated developmental signaling pathways. Moreover, they had increased rapidity of tumor growth potential and invasiveness, in comparison to CD24, CD44, ESA-negative cancer cells [140]. Li et al. showed that CD44+CD24+ESA+CSC clearly exhibits different morphology to that seen in common PC cells. In addition to cellular alternations related to the individual aforementioned CSC markers, the expression of these markers are strictly related to the hedgehog (hh) signaling pathway due to upregulation of Sonic hedgehog protein expression and its exudation outside the cell [139]. High concentrations of this protein in the PC microenvironment is associated with increases in CD44+CD24+ESA+ cells in the cancer mass. The deregulation of the hh pathway probably leads to transformation of adult stem cells of the pancreatic glands into CSC [141]. Recent studies have suggested that the expression of other CSC markers such as DCLK1 and CD133 may correlate with triple-positive expression of CD44/CD24/EpCAM in this cancer type [82] [142]. This observation could indicate that the majority of CSC markers in PC are strongly associated with each other. In addition Skoda et al. found that the highest proportions of CD24+CD44+EpCAM+CD133+ cells could be detected in cell lines derived from the tumors of patients with the shortest survival [142]. Deregulation of the Wnt pathway in the form of upregulation WNT2B has been detected in these cells. Upregulated expression of LYN, and downregulation of FYN expression have been also observed in this cell population [142]. As earlier discussed, both alternatives on this pathway seem to be associated with CD133 expression and cases with cells with more than one CSC marker could be also related to this protein. Co-expression of CD44/CD133 was significantly related to poor 5-year of overall survival of patients, as was CA 19-9 levels [46]. This short summary 
suggests that there exists a wide complexity of interactions and relationships between CSC markers in PC. Understanding these dependences would seem to be of importance in cases where the influence of the aforementioned proteins may affect treatment strategy. All the molecular pathways related to CSC markers in PC are graphically summarized in Fig. 1.

\section{CSC as a cause of resistance to standard chemotherapy in pancreatic cancer}

Most current therapies for the treatment of PC do not affect CSCs, which can result in the reestablishment of tumors after traditional treatment. Growing evidence seems to confirm the resistance of pancreatic CSCs to treatment with gemcitabine [143]. Researchers have shown that high CD44+ PC developed resistance to gemcitabine after 12 weeks of treatment, whereas cases of low CD44 positive PC were sensitive through 22 weeks of therapy. This fact suggests, that CD44+ PC cells may be gemcitabine resistant. Moreover, it could be possible that the level of CD44 overexpression may predict the time of resistance to chemotherapy. Also, the ability of PC to recur can be explained by the observation that CD44+ PC cells are characterized more by their tumorigenic potential than as cells with higher gemcitabine sensitivity. The study showed that anti-CD44 therapy was effective in the recurrence PCs. Studies have also revealed, that the knocking down of CD44 in CD44 high PC caused decreased invasiveness and increased sensitivity to gemcitabine $[102,144]$. CSCs are naturally resistant to chemotherapy through their quiescence, capacity for DNA repair and ATP-binding cassette (ABC) transporter expression [145]. The mechanism of drug resistance in CSCs is mostly reported in relation to $\mathrm{ABC}$ transporters. The overexpression of these proteins increases drug efflux, thereby reducing intracellular drug levels and, therefore its biological effect [146]. Among ABC transporters, ABCB1 (MDR1) was significantly augmented during the acquisition of drug resistance, and in many studies co-expression of these proteins with CD44 has been shown after exposure to gemcitabine [102,147-149]. Thus, a therapy based on verapamil, an inhibitor of $A B C$ transporters such as $\mathrm{ABCB} 1$, to sensitize gemcitabine resistant cells to gemcitabine, together with anti-CD44 siRNA, caused a significant decrease in CD44+PC cells [150]. After binding of HA to CD44 the expression of the homeobox protein Nanog is activated, whereupon this protein forms a complex with another CD44-overexpressed protein STAT3 and induces activation of ABCB1 transporter transcription [148]. Understanding of another molecular mechanism for PC resistance to gemcitabine stays remains unexplained. In this process, many genes are involved, related both to nucleoside transport or metabolism (M1 or M2 subunits of ribonucleoside reductase) and to cell cycle regulation, proliferation or apoptosis. These include mutated, Bcl-xl, Proto-oncogene tyrosineprotein kinase $\mathrm{Src}(\mathrm{Src})$, focal adhesion kinase and p53 [151-155]. Earlier we noted that the loss of functional p53 is one of the triggers of CD44 overexpression. Moreover, cancer cells lacking p53 activity become insensitive to gemcitabine, owing to the loss of cell cycle control and alterations in the apoptotic cascade [154]. Other molecular events during the acquisition of resistance to gemcitabine in PC include the upregulation of c-MET and STAT3, which are accompanied by CD44 upregulation and downregulation of the Src family protein as well as increased autocrine production of EGFR ligand amphiregulin and, as a consequence, hyperactivity of EGFR [156]. Autocrine epidermal growth factor receptor (EGFR) signaling is also upregulated by $\mathrm{NRF} 2$, a transcription factor that is overexpressed during oxygen stress in cancer cells [157]. One of the gemcitabineinduced effects in affected cancer cells is the production of reactive oxygen species (ROS) [158, 159]. In response to this, the expression of antioxidant agents, such as glutathione (GSH) and heme oxygenase 1 (HO-1) increases in $\mathrm{PC}$ cells due to activation of the transcription factor NRF2 and results in a reduction in intracellular ROS [157, 160, 161]. Inhibition of HO-1 reduced expression of the CSC markers CD133, and CD44, which may suggest that the avoidance of ROS-related injuries of PC cells during gemcitabine treatment is related to the stemness abilities of the cells and specifically to CD44 + positive CSC in PC [41]. The influence of EGFR signaling could explain the process of intensive repopulation of CSCs after gemcitabine treatment. The mechanisms for gemcitabine resistance in CD44+ cells are summarized in Fig. 2. The latest studies have additionally shown that not only CD44+PC CSC but also CD24+CD44+ESA+ and CD24+cells are resistant to gemcitabine [162] [140, 163, 164]. In these cells there additional mechanisms have been detected for both gemcitabine and 5 fluorouracil resistance related to pancreatic adenocarcinoma up-regulated factor (PAUF), which increased the mRNA expression of multidrug resistant protein 5 (MRP5) and ribonucleotide reductase M2 (RRM2) [165]. These alternations result not only in chemotherapeutic efflux from cells, but also accelerate the formation of deoxyribonucleotides from ribonucleotides, which supports proliferation of cancer cells. Moreover, PAUF seems to take part in the activation of transcription of another CSC marker, namely CD133 [165]. In a previous study of this CSC marker, that is CD133, gemcitabine decreased only the viability of CD133- cells at higher concentrations, no therapeutic effects were observed among CD133+ PC cells regardless of the drug concentration used [42, 47, 53, 166]. The influence of CD133 on cancer cell biology may be mainly due to metabolic pathways. The characteristic localization for 


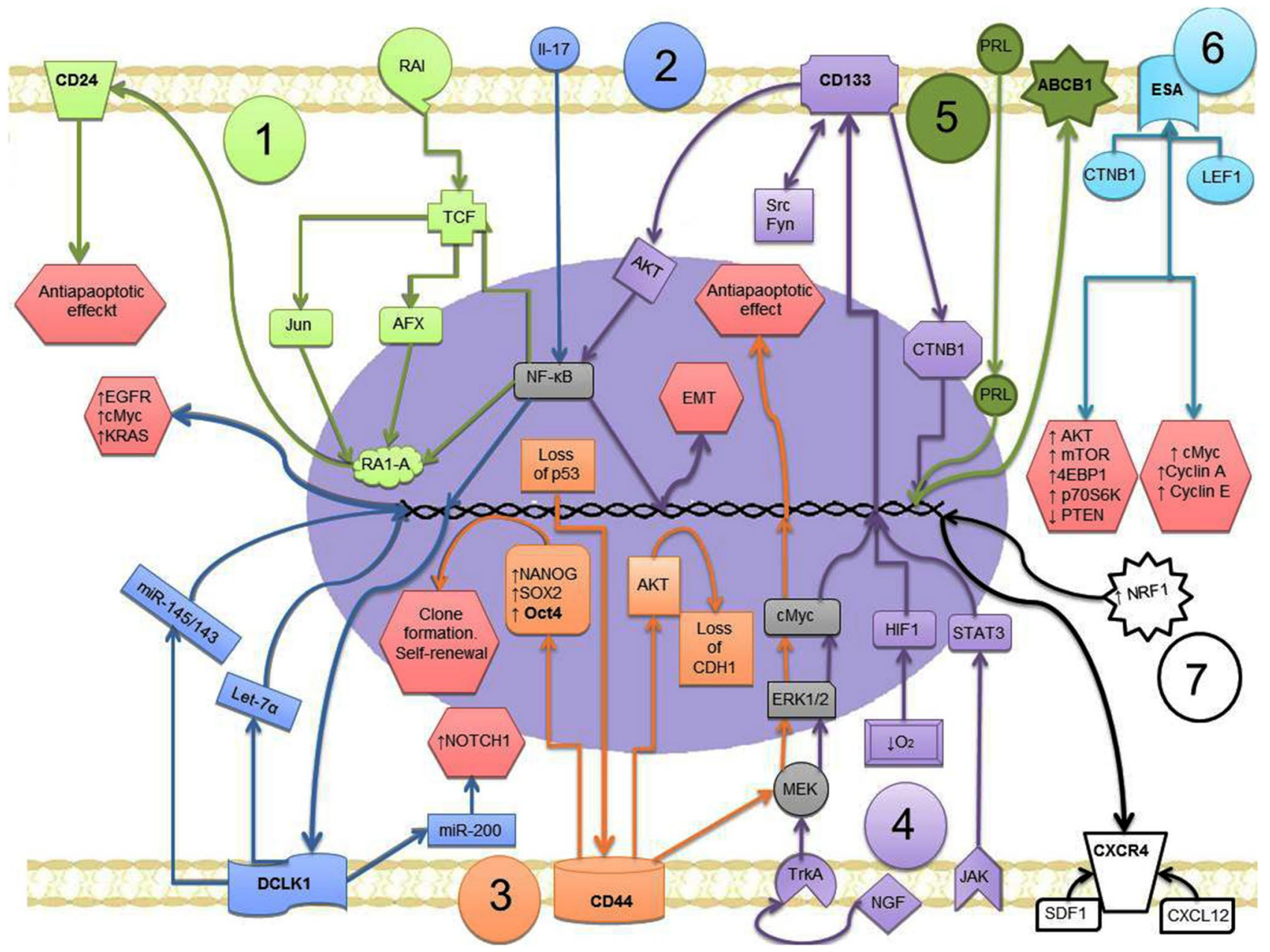

Fig. 1 Molecular pathways related to cancer stem cells markers in pancreatic cancer cell $[25-28,31,35-45,48,49,59,61-64$, 69-71, 87, 90-98, 108, 109, 112, 113, 127, 128, 132, 133]. (1) Ral GTPases initiates transcription of CD24 through TCF downstream pathways and activation of transcription Jun, NF- $\mathrm{BB}$, AFX, which regulates the expression of CD24 in conjunction with Ras-related protein RalA. The overexpression of $\mathrm{CD} 24$ protects cancer cells from the apoptotic process. (2) The upregulation of DCLK1 is promoted by immune cell-derived IL17 which increases DCLK1 expression through activation of nuclear factor $\mathrm{kB}(\mathrm{NF}-\mathrm{kB})$. The overexpressed DCLK1 promotes tumorigenesis through the upregulation of $\mathrm{cMyc}$ and KRAS through a let-7a microRNA(let-7a)-dependent mechanism and cell proliferation by overexpression of EGFR through a miR145/143-dependent mechanism. DCLK1 downregulates the miR-200 family, which causes activation of the NOTCH pathway. (3) The loss-of-function mutation of p53 leads to up-regulation of CD44 in pancreatic cancer cells. Overexpression of CD44 activates c-Myc, which leads to MEK and Erk pathway activation and decreases apoptosis. Activated CD44 triggers the Akt pathway which inhibits E-cadherin expression and induces EMT. Moreover, overexpression of CD44 also leads to upregulation of Nanog, Sox 2 and Oct4, which results in increased spheroid and clone formation as well as cell growth/self-renewal. (4) The triggering of the TrkA receptor in response to auto- or paracrine excreted Nerve growth factor (NGF) activates the MAPK/ERK pathway and leads to the CD133 transcription pathway, as initiated by one of the extracellular signal-regulated kinases (ERKs), mainly by ERK1 or ERK1. CD133 expression is also induced in pancreatic cancer by the heat shock proteins HIF-1 $\alpha$ and HIF- $2 \alpha$ or by hyperactivity of Janus kinases (JAK) or by the Signal Transducer and Activator of Transcription protein 3 (STAT3). CD133 is a substrate proto-oncogene of the tyrosine-protein kinases Src and Fyn, which phosphorylate its cytoplasmic domain and increase downstream signaling in the form of Akt phosphorylation, which cause NF- $\mathrm{KB}$ activation and induction of epithelial-mesenchymal transition (EMT). CD133 activates $\mathrm{WNT} / \beta$ catenin signaling. (5) WNT/ $\beta$-catenin signaling and leptins from the pancreatic cancer microenvironment trigger transcription of $A B C B 1$. (6) EpCAM (ESA) intracellular domains form a complex with $\beta$-catenin and LEF-1, which causes transcription of genes such as c-Myc, and the cyclins $\mathrm{A}$ and E. Its overexpression increased the phosphorylation of AKT, mTOR, p70S6K and 4EBP1and also decreased PTEN expression, also EpCAM regulates EMT and metastasis. (7) Nuclear Respiratory Factor 1 (NRF1) regulates the expression of CXCR4. Expression of CXCR4 on the surface of cancer cells can direct tumor metastases towards SDF-1 expressing tissues via the SDF-1-CXCR4 axis. Moreover, CXCR4 joins with CXC12 leading to the migration of cells and the formation of metastases 


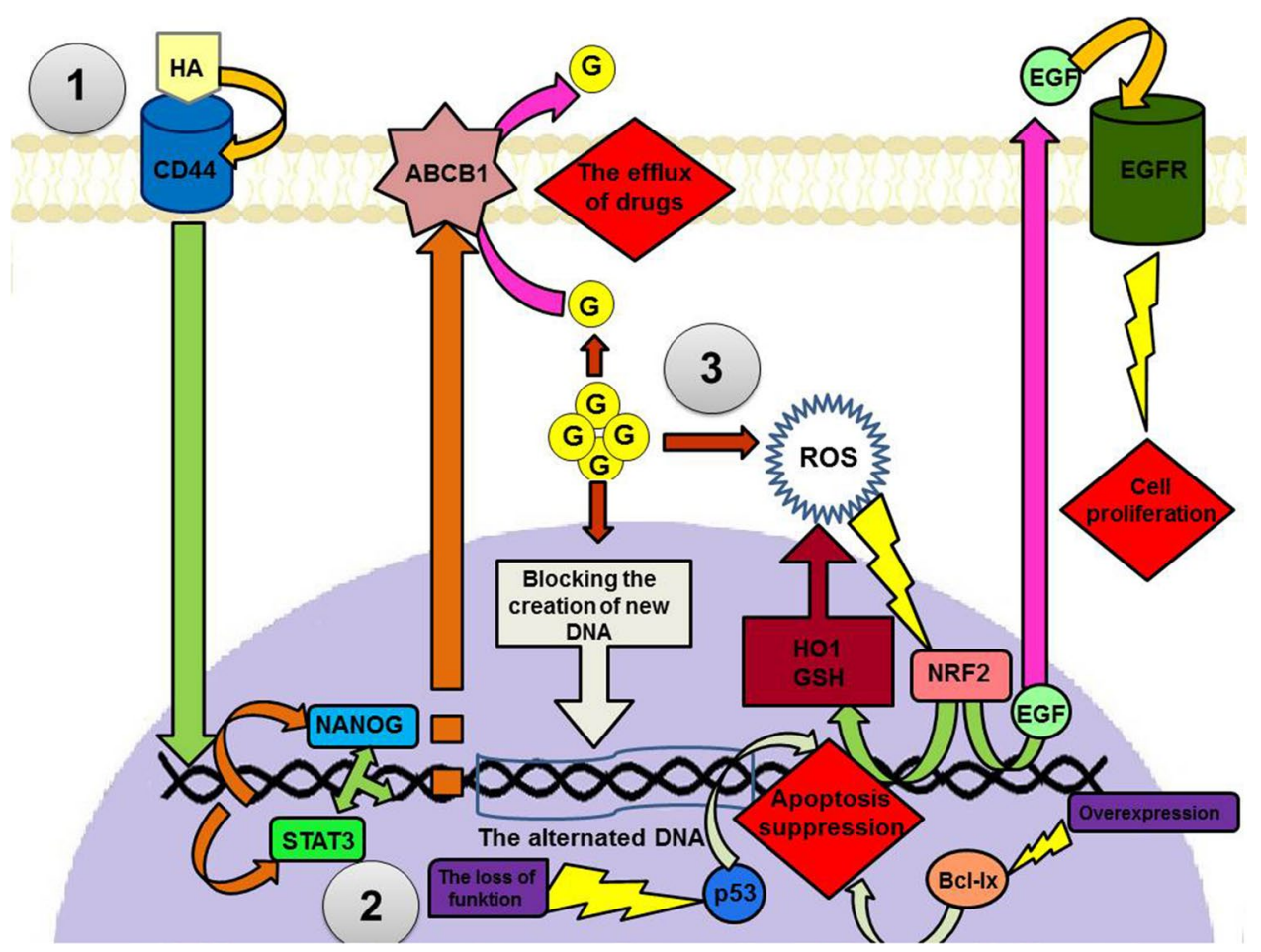

Fig. 2 Molecular mechanism of $\mathrm{CD} 44+$ cell resistance to gemcitabine [146, 148, 151-161]. (1) After the binding of HA to CD44, the expression of the homeobox protein Nanog is activated, whereupon this protein makes a complex with another CD44-overexpressed protein, STAT3, and induces the activation of ABCB1 transporter transcription. The overexpression of these proteins increases drug efflux, thereby reducing intracellular drug levels and therefore their biological effects. (2)The lack of p53 activity in cells reduces their sensitivity to gemcitabine due to the loss of cell cycle control and alterations

CD133+ cells is in the hypoxic regions of the tumor, which are associated with increasing hypoxia-inducible factor 1 (HIF1) activity. HIF1 increases glucose uptake in these cells, and upregulates glycolysis enzymes, which allows for ATP synthesis in low-oxygen conditions [42]. It might also have effects on the neovascularization of PC. Moreover, in CD133+ cells low mitochondrial activity has been detected, in spite of having physiologically healthy mitochondria [42]. This altered metabolic profile of CD133+ cells make them resistant to ROS injury caused by gemcitabine and consequently to this form of chemotherapy. The glycolysis also induces expression of the CSC marker DCLK1, which is therefore also related to gemcitabine resistance [167].

CD133+ cells show increased expression of anti-apoptotic genes such as Bcl-2 [47]. Another study suggested that the reoccurrence of $\mathrm{PC}$ after treatment with gemcitabine was composed of mainly CD44+ cells, compared to the number of CD133+ and ESA+ cells [150]. This observation add weight to the previously described supposition that CD44 not only upregulates cancer cell survival pathways, but also accelerates the proliferation of CSC. In summary, clinical in the apoptotic cascade. The antiapoptotic effect is also induced by mutation of Bcl-xl, with similar effects on gemcitabine sensitivity. (3) In response to gemcitabine-induced production of reactive oxygen species (ROS) the transcription factor NRF2 is activated, which results in the expression of antioxidant agents, such as glutathione (GSH) and heme oxygenase 1 (HO-1) resulting in a reduction of intracellular ROS and prevention of injuries caused by it. Moreover, NRF2 stimulates autocrine epidermal growth factor receptor (EGFR) signaling and therefore upregulates proliferative signals

studies in genetics suggest that CD44+cells are able to proliferate at a faster rate, which enables their dominancy in tumor recurrence. Not only gemcitabine, but also other standard anticancer drugs are ineffective in PC with CSCs. Studies revealed that CD133+ cells also seem to be resistant to 5FU and nab-paclitaxel, which only reduce the population of CD133- cells but without having any effect on CD133+cells [42, 47]. These effects seems to be caused by $\mathrm{ABC}$ transporters, which have the ability, in the case of CD133+ cells, to dispose not only of Gemcitabine, as is the case with CD44+ cells, but also Paclitaxel and 5FU [47]. To explain why this phenomenon has been observed only in DC133+ cells requires additional studies, however.

The molecular observations described above may be suitable for use in clinical practice. A retrospective multicenter study including 1056 patients with metastatic PC showed that the median overall survival is dependent on the palliative chemotherapeutic cycle used, and on the use of FOLFIRINOX for up to 9.9 months, nab-paclitaxel with gemcitabine for 7.9 months, and 4.9 months of gemcitabine monotherapy [168]. Similarly, an adjuvant treatment study 
among a population of 493 patients, by Conroy et al. showed that this kind of therapy with a FOLFIRINOX regimen led to significantly longer survival (54.4 months) than gemcitabine (35.0 months) [169]. Furthermore, the overall survival rate at 3 years was $63.4 \%$ in the modified-FOLFIRINOX group and $48.6 \%$ in the gemcitabine group. These results could be explained by the tendency of CSCs, and above all CD44+CSCs, to be insensitive to gemcitabine treatment. The visibly shorter survival period of patients who were treated with this drug, in comparison to remaining options, may be associated with the drug related selection of CD44+ cells and their unlimited proliferation. In the case of combined nab-paclitaxel and gemcitabine treatment, the longer survival rate in comparison to gemcitabine alone might arise from the sensitivity of CD44+ cells to nabpaclitaxel, whose proliferation is stopped with this drug. However, given that the PC resistance to gemcitabine might be explained by well described CSCs features, in a mostly CD44+ subpopulation, the sensitivity of these cells population to FOLFIRINOX needs further studies. The progression of disease during chemotherapeutic treatment may be the result of CD133+ proliferation, which could indicate resistance to both nab-paclitaxel and gemcitabine, and could become dominant in the CSC population, while CD44+ cells are eliminated.

\section{New possibility of pancreatic cancer treatment based on CSC-targeting factors}

The relationship between PC chemotherapy resistance and CSC markers described above leads us to conclude that the targeting of these proteins may increase both disease-free and overall survival periods for patients with this neoplasm. A study revealed that CD24 monoclonal antibodies inhibited the growth of human high CD24+ PCs in relation to both time and dose of exposure [140]. Furthermore, the group's next study showed that anti-CD24 antibodies might enhance the effects of oxaloplatin, 5-fluorouracil, doxorubicin, irinotecan, and paclitaxel on the reduction of CD24+ cells [139]. Moreover, Shah et al. observed that CD24+, CD44+, and ESA+ cells were more invasive and exhibited increased activation of c-Met, which is one of the potential CSC targets [163]. The c-Met inhibitor with gemcitabine reduced the population of CD24+, CD44+, and ESA+ cells, decreased tumor sphere formation in these cells and prevented the growth of the tumor for 6 weeks after the therapy. The authors suggested that the combined use of c-Met inhibitor and gemcitabine might be an effective treatment of PC, due to effects on CSC and bulk PC cell populations [19]. Furthermore, the research of Mueller et al. showed that a combination of cyclopamine/CUR, rapamycin, and gemcitabine may cause tumor regression and abolishes CD24+ CD44+ ESA+ and CD133+ CSC subpopulations with a better survival rate after a 100 days of observation in comparison to gemcitabine only [170]. Moreover, their studies suggested that metformin could inhibit the proliferative activity of CD133+ PC cells leading to decreased pancreatic tumor weights by as much as $34-49 \%$ according to drug concentration [54, 171, 172]. On the other hand, the influence of metformin did not affect PC stem cells with other CSC markers, such as $\mathrm{CD} 24+, \mathrm{CD} 44+, \mathrm{ESA}+$ and co-expression of them [54]. Gupta et al. also showed significantly lower tumor volume among PCs with an initially high population of CD133+ cells (10-25\% of cells) in mice treated with lovastatin in combination with paclitaxel when compared to a control group, which suggests that lovastatin may sensitize these cells to paclitaxel [173]. In the Rangarajan et al. study it was found that crocetinic acid suppressed the growth of the tumor and the expression of CD133 and DCLK1 [174]. Another interesting result observed during a study with the kinase inhibitor XMD8-92, showed that injecting this drug caused a reduction in xenograft volume and weight, as well as significant downregulation of DCLK1 expression [175]. In a recent study, significantly reduced cell survival in cases of combined treatment of PC with gemcitabine and DCLK1 inhibitor was demonstrated, compared to individual treatment with gemcitabine in a cell line model [176]. Interestingly, a study by Cioffi et al. described finding that EpCAM/CD3Bispecific T cell Engaging Antibody MT110 may eliminate primary human pancreatic CSCs in vivo and in vitro, due to the redirection of cytotoxic $\mathrm{T}$ lymphocytes against human pancreatic CSCs. As a result, it induced apoptosis, inhibited sphere formation and reduced tumorigenicity of PC in mice. Additionally, the authors observed that the addition of gemcitabine caused no further reduction of tumor size [143]. Another substance, namely acetyl11-keto-b-boswellic, could be useful in the suppression of progression in CXCR4+ cancer due to downregulation of the CXCR4 receptor and by reduction of the invasiveness of PC [177]. On the other hand, Wang and al. have shown that a blocking ligand binding to CXCR4 had positive effects, not only by reducing PC growth, but also by increasing the sub-G1 apoptotic compartment, thus affecting the G0-G1 phase and, by extension, slowing the G2 and $\mathrm{S}$ phases [178]. Moreover, because knockdown of CXCR4 and OCT4 decreases the invasiveness of PC, these factors may also be a promising point in the future of PC therapy [178] [179] Equally interesting are the results of Gao et al. in which it was shown that there is less microRNA-335 to be found in OTC4 (+) PC cells than in OCT4 $(-)$ cells and that miR-335 may cause OCT4 suppression, 


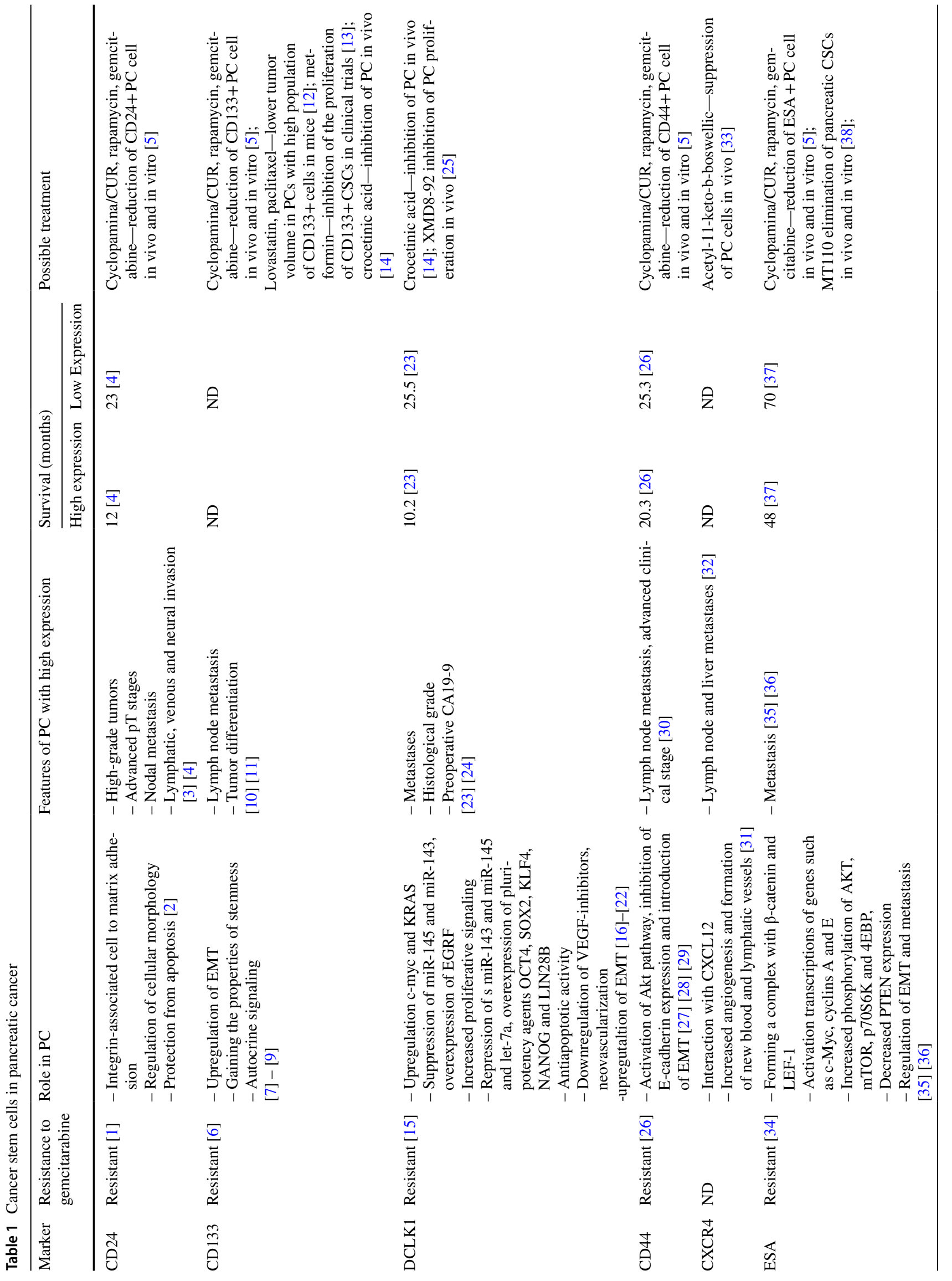


which in turn results in slower development and decreased tumor expansion [179].

\section{Summary}

The expression of PC stem cell markers such as CD133, CD24, CD44, DCLK1, CXCR4, ESA, Oct4 and ABCB1 could be negative prognostic factors in $\mathrm{PC}$ and are responsible for its faster progression and its resistance to standard treatment. The expression of these factors may be responsible for the reduction of overall-survival and 5-year survival. Moreover, it seems to be proven that the expression of CD24, CD133, DCLK1, CD44, CXCR4, and Oct4 are associated with a higher incidence of lymph node metastasis, whereas CD24 is also responsible for microscopic, lymphatic, venous and neuronal invasion. The expression of CD44, CD24, ESA and CD133 could also be largely involved in the resistance of PC to gemcitabine therapy, and thus the targeting of these proteins may increase both disease-free and overall survival in PC. All conclusions of our review are summarized in Table 1.

\section{Compliance with the ethical standards}

Conflict of interest The authors declare that they have no conflict of interest.

Ethical approval For this type of study formal consent is not required.

Open Access This article is distributed under the terms of the Creative Commons Attribution 4.0 International License (http://creativecommons.org/licenses/by/4.0/), which permits unrestricted use, distribution, and reproduction in any medium, provided you give appropriate credit to the original author(s) and the source, provide a link to the Creative Commons license, and indicate if changes were made.

\section{References}

1. Siegel RL, Miller KD, Jemal A (2017) Cancer Statistics, 2017. CA Cancer L Clin 67:7-30. https://doi.org/10.3322/caac.21387

2. World Cancer Report (2014) World Health Organization 2014. Chapter 5.7. ISBN 978-92-832-0429-9

3. De Craene B, Berx G (2013) Regulatory networks defining EMT during cancer initiation and progression. Nat Rev Cancer 13(2):97

4. Krejs GJ (2010) Pancreatic cancer: epidemiology and risk factors. Dig Dis 28:355-358. https://doi.org/10.1159/000319414

5. Maisonneuve P, Lowenfels AB (2014) Risk factors for pancreatic cancer: a summary review of meta-analytical studies. Int J Epidemiol 44(1):186-198

6. Yu W, Ma Y, Shankar S, Srivastava RK (2018) Chronic ethanol exposure of human pancreatic normal ductal epithelial cells 
induces cancer stem cell phenotype through SATB2. J Cell Mol Med 22:3920-3928. https://doi.org/10.1111/jcmm.13666

7. Ning X, Shu J, Du Y et al (2013) Therapeutic strategies targeting cancer stem cells. Cancer Biol Ther 14:295-303. https://doi. org/10.4161/cbt.23622

8. Hermann PC, Huber SL, Herrler T et al (2007) Distinct populations of cancer stem cells determine tumor growth and metastatic activity in human pancreatic cancer. Cell Stem Cell 1:313-323. https://doi.org/10.1016/j.stem.2007.06.002

9. Mimeault M, Hauke R, Mehta PP, Batra SK (2007) Recent advances in cancer stem/progenitor cell research: therapeutic implications for overcoming resistance to the most aggressive cancers. J Cell Mol Med 11:981-1011. https://doi.org/10.111 1/j.1582-4934.2007.00088.x

10. Reya T, Morrison SJ, Clarke MF, Weissman IL (2001) Stem cells, cancer and cancer stem cells. Nature 414:105-111. https ://doi.org/10.1038/35102167

11. Ajani JA, Song S, Hochster HS, Steinberg IB (2015) Cancer stem cells: the promise and the potential. Semin Oncol 42:S3-S17. https://doi.org/10.1053/j.seminoncol.2015.01.001

12. Ishiwata T, Matsuda $\mathrm{Y}$, Yoshimura H et al (2018) Pancreatic cancer stem cells: features and detection methods. Pathol Oncol Res 24:797-805. https://doi.org/10.1007/s12253-018-0420-x

13. Van den Broeck A, Vankelecom H, Van Delm W et al (2013) Human pancreatic cancer contains a side population expressing cancer stem cell-associated and prognostic genes. PLoS ONE 8:e73968. https://doi.org/10.1371/journal.pone.0073968

14. Lee I-C, Wu Y-C, Hung W-S (2018) Hyaluronic acid-based multilayer films regulate hypoxic multicellular aggregation of pancreatic cancer cells with distinct cancer stem-cell-like properties. ACS Appl Mater Interfaces 10:38769-38779. https://doi. org/10.1021/acsami.8b14006

15. Vinogradov S, Wei X (2012) Cancer stem cells and drug resistance: the potential of nanomedicine. Nanomedicine 7:597-615. https://doi.org/10.2217/nnm.12.22

16. Renouf D, Moore M (2010) Evolution of systemic therapy for advanced pancreatic cancer. Expert Rev Anticancer Ther 10:529540. https://doi.org/10.1586/era.10.21

17. Oettle H, Neuhaus $P$ (2007) Adjuvant therapy in pancreatic cancer. Drugs 67:2293-2310. https://doi.org/10.2165/00003495200767160-00001

18. Oken MM, Creech RH, Tormey DC et al (1982) Toxicity and response criteria of the Eastern Cooperative Oncology Group. Am J Clin Oncol 5:649-655

19. Ducreux M, Sa Cuhna A, Caramella C et al (2015) Cancer of the pancreas: ESMO Clinical Practice Guidelines for diagnosis, treatment and follow-up. Ann Oncol 26:56-68. https://doi. org/10.1093/annonc/mdv295

20. Conroy T, Gavoille C, Samalin E et al (2013) The role of the FOLFIRINOX regimen for advanced pancreatic cancer. Curr Oncol Rep 15:182-189. https://doi.org/10.1007/s1191 2-012-0290-4

21. Faris JE, Blaszkowsky LS, McDermott S et al (2013) FOLFIRINOX in locally advanced pancreatic canCER: the Massachusetts General Hospital Cancer Center experience. Oncologist 18:543-548. https://doi.org/10.1634/theoncologist.2012-0435

22. Von Hoff DD, Ervin T, Arena FP et al (2013) Increased survival in pancreatic cancer with nab-paclitaxel plus gemcitabine. N Engl J Med 369:1691-1703. https://doi.org/10.1056/NEJMo a1304369

23. Droz D, Zachar D, Charbit L et al (1990) Expression of the human nephron differentiation molecules in renal cell carcinomas. Am J Pathol 137:895-905

24. Poncet C, Frances V, Gristina R et al (1996) CD24, a glycosylphosphatidylinositol-anchored molecule, is transiently expressed during the development of human central nervous system and is a marker of human neural cell lineage tumors. Acta Neuropathol. https://doi.org/10.1007/s004010050442

25. Smith SC, Oxford G, Wu Z et al (2006) The metastasis-associated gene CD24 is regulated by Ral GTPase and is a mediator of cell proliferation and survival in human cancer. Cancer Res. https://doi.org/10.1158/0008-5472.CAN-05-3855

26. Feig LA (2003) Ral-GTPases: approaching their 15 minutes of fame. Trends Cell Biol 13:419-425. https://doi.org/10.1016/ S0962-8924(03)00152-1

27. Lim K-H, Baines AT, Fiordalisi JJ et al (2005) Activation of RalA is critical for Ras-induced tumorigenesis of human cells. Cancer Cell 7:533-545. https://doi.org/10.1016/j.ccr.2005.04.030

28. Moghadam AR, Patrad E, Tafsiri E et al (2017) Ral signaling pathway in health and cancer. Cancer Med 6:2998-3013. https ://doi.org/10.1002/cam4.1105

29. Jacob J, Bellach J, Grützmann R et al (2004) Expression of CD24 in adenocarcinomas of the pancreas correlates with higher tumor grades. Pancreatology 4:454-460. https://doi.org/10.1159/00007 9824

30. Ikenaga N, Ohuchida K, Mizumoto K et al (2010) Characterization of CD24 expression in intraductal papillary mucinous neoplasms and ductal carcinoma of the pancreas. Hum Pathol 41:1466-1474. https://doi.org/10.1016/j.humpath.2010.04.004

31. Boivin D, Labbé D, Fontaine N et al (2009) The stem cell marker CD133 (prominin-1) is phosphorylated on cytoplasmic tyrosine- 828 and tyrosine- 852 by Src and Fyn tyrosine kinases. Biochemistry 48:3998-4007. https://doi.org/10.1021/bi900159d

32. Taïeb N, Maresca M, Guo X-J et al (2009) The first extracellular domain of the tumour stem cell marker CD133 contains an antigenic ganglioside-binding motif. Cancer Lett 278:164-173. https://doi.org/10.1016/j.canlet.2009.01.013

33. Röper K, Corbeil D, Huttner WB (2000) Retention of prominin in microvilli reveals distinct cholesterol-based lipid micro-domains in the apical plasma membrane. Nat Cell Biol 2:582-592. https ://doi.org/10.1038/35023524

34. Giebel B, Corbeil D, Beckmann J et al (2004) Segregation of lipid raft markers including CD133 in polarized human hematopoietic stem and progenitor cells. Blood 104:2332-2338. https ://doi.org/10.1182/blood-2004-02-0511

35. Ohnishi S, Maehara O, Nakagawa K et al (2013) Hypoxia-inducible factors activate CD133 promoter through ETS family transcription factors. PLoS ONE 8:e66255. https://doi.org/10.1371/ journal.pone.0066255

36. Tabu K, Kimura T, Sasai K et al (2010) Analysis of an alternative human CD133 promoter reveals the implication of Ras/ERK pathway in tumor stem-like hallmarks. Mol Cancer 9:39. https:// doi.org/10.1186/1476-4598-9-39

37. Sasagawa S, Ozaki Y, Fujita K, Kuroda S (2005) Prediction and validation of the distinct dynamics of transient and sustained ERK activation. Nat Cell Biol 7:365-373. https://doi. org/10.1038/ncb1233

38. Xin B, He X, Wang J et al (2016) Nerve growth factor regulates CD133 function to promote tumor cell migration and invasion via activating ERK1/2 signaling in pancreatic cancer. Pancreatology 16:1005-1014. https://doi.org/10.1016/j.pan.2016.09.005

39. Nagathihalli NS, Castellanos JA, Lamichhane P et al (2018) Inverse correlation of STAT3 and MEK signaling mediates resistance to Ras pathway inhibition in pancreatic cancer. Cancer Res 78:6235-6246. https://doi.org/10.1158/0008-5472.CAN-18-0634

40. Soeda A, Park M, Lee D et al (2009) Hypoxia promotes expansion of the CD133-positive glioma stem cells through activation of HIF-1 $\alpha$. Oncogene 28:3949-3959. https://doi.org/10.1038/ onc. 2009.252

41. Abdalla MY, Ahmad IM, Rachagani S et al (2019) Enhancing responsiveness of pancreatic cancer cells to gemcitabine 
treatment under hypoxia by heme oxygenase-1 inhibition. Trans1 Res 207:56-69. https://doi.org/10.1016/j.trsl.2018.12.008

42. Nomura A, Dauer P, Gupta V et al (2016) Microenvironment mediated alterations to metabolic pathways confer increased chemo-resistance in CD133+ tumor initiating cells. Oncotarget 7:56324-56337. https://doi.org/10.18632/oncotarget.10838

43. Zhan T, Rindtorff N, Boutros M (2017) Wnt signaling in cancer. Oncogene 36:1461-1473. https://doi.org/10.1038/onc.2016.304

44. Jiang X, Hao H-X, Growney JD et al (2013) Inactivating mutations of RNF43 confer Wnt dependency in pancreatic ductal adenocarcinoma. Proc Natl Acad Sci 110:12649-12654. https ://doi.org/10.1073/pnas.1307218110

45. Chen X, Cheng F, Liu Y, et al (2019) Toll-like receptor 2 and Toll-like receptor 4 exhibit distinct regulation of cancer cell stemness mediated by cell death-induced high-mobility group box 1-NC-ND license (http://creativecommons.org/ licenses/by-nc-nd/4.0/). EBioMedicine 40:135-150. https:// doi.org/10.1016/j.ebiom.2018.12.016

46. Hou Y-C, Chao Y-J, Tung H-L et al (2014) Coexpression of CD44-positive/CD133-positive cancer stem cells and CD204positive tumor-associated macrophages is a predictor of survival in pancreatic ductal adenocarcinoma. Cancer 120:27662777. https://doi.org/10.1002/cncr.28774

47. Banerjee S, Nomura A, Sangwan V et al (2014) CD133 + tumor initiating cells (TIC) in a syngenic murine model of pancreatic cancer respond to Minnelide. Clin Cancer Res 20:2388-2399. https://doi.org/10.1158/1078-0432.CCR-13-2947

48. Chen Y-S, Wu M-J, Huang C-Y et al (2011) CD133/Src axis mediates tumor initiating property and epithelial-mesenchymal transition of head and neck cancer. PLoS ONE 6:e28053. https ://doi.org/10.1371/journal.pone.0028053

49. Weng C-C, Kuo K-K, Su H-T et al (2016) Pancreatic tumor progression associated with CD133 overexpression. Pancreas 45:443-457. https://doi.org/10.1097/MPA.000000000000046 0

50. Huber MA, Azoitei N, Baumann B et al (2004) NF- $\kappa B$ is essential for epithelial-mesenchymal transition and metastasis in a model of breast cancer progression. J Clin Invest 114:569-581. https://doi.org/10.1172/JCI21358

51. Nomura A, Banerjee S, Sangwan V et al (2015) CD133 initiates tumors, induces epithelial-mesenchymal transition, and increases metastasis in pancreatic cancer. Cancer Res 75:A24-A24. https ://doi.org/10.1158/1538-7445.panca2014-a24

52. Nomura A, Gupta VK, Dauer P et al (2018) NFkB-mediated invasiveness in CD133+ pancreatic TICs is regulated by autocrine and paracrine activation of IL1 signaling. Mol Cancer Res 16:162-172. https://doi.org/10.1158/1541-7786.MCR-17-0221

53. Hermann PC, Huber SL, Herrler T et al (2007) Cell stem cell article distinct populations of cancer stem cells determine tumor growth and metastatic activity in human pancreatic cancer. Cell Stem Cell. https://doi.org/10.1016/j.stem.2007.06.002

54. Chen K, Li Z, Jiang P et al (2014) Co-expression of CD133, CD44v6 and human tissue factor is associated with metastasis and poor prognosis in pancreatic carcinoma. Oncol Rep 32:755763. https://doi.org/10.3892/or.2014.3245

55. Durko L, Wlodarski W, Stasikowska-Kanicka O et al (2017) Expression and clinical significance of cancer stem cell markers CD24, CD44, and CD133 in pancreatic ductal adenocarcinoma and chronic pancreatitis. Dis Markers. https://doi. org/10.1155/2017/3276806

56. Fu Y, Plentz R, Zhang H et al (2015) DCLK1 marks a morphologically distinct subpopulation of cells with stem cell properties in pre-invasive pancreatic cancer. Gastroenterology 146:245256. https://doi.org/10.1053/j.gastro.2013.09.050.DCLK1
57. Szymanski CJ, Munusamy P, Mihai C et al (2016) HHS public access. Biomaterials 62:147-154. https://doi.org/10.1016/j. biomaterials.2015.05.042.Shifts

58. Qiu W, Remotti HE, Tang SM et al (2018) Pancreatic DCLK1+cells originate distinctly from PDX1+ progenitors and contribute to the initiation of intraductal papillary mucinous neoplasm in mice. Cancer Lett 423:71-79. https://doi.org/10.1016/j. canlet.2018.03.009

59. Zhang Y, Zoltan M, Riquelme E et al (2018) Immune cell production of interleukin 17 induces stem cell features of pancreatic intraepithelial neoplasia cells. Gastroenterology 155:210-223.e3. https://doi.org/10.1053/j.gastro.2018.03.041

60. Zhou B, Sun C, Hu X et al (2017) MicroRNA-195 suppresses the progression of pancreatic cancer by targeting DCLK1. Cell Physiol Biochem 44:1867-1881. https://doi.org/10.1159/00048 5876

61. Sureban SM, May R, Qu D et al (2013) DCLK1 regulates pluripotency and angiogenic factors via microRNA-dependent mechanisms in pancreatic cancer. PLoS ONE 8:73940. https://doi. org/10.1371/journal.pone.0073940

62. Sureban SM, May R, Lightfoot SA et al (2011) DCAMKL-1 regulates epithelial-mesenchymal transition in human pancreatic cells through a miR-200a-dependent mechanism. Cancer Res 71:2328-2338. https://doi.org/10.1158/0008-5472.CAN-10-2738

63. Sureban SM, May R, Ramalingam S et al (2009) Selective blockade of DCAMKL-1 results in tumor growth arrest by a Let-7a MicroRNA-dependent mechanism. Gastroenterology 137:649659.e2. https://doi.org/10.1053/j.gastro.2009.05.004

64. Skoudy A, Hernández-Muñoz I, Navarro P (2011) Pancreatic ductal adenocarcinoma and transcription factors: role of c-Myc. J Gastrointest Cancer 42:76-84. https://doi.org/10.1007/s1202 9-011-9258-0

65. di Magliano MP, Logsdon CD (2013) Roles for KRAS in pancreatic tumor development and progression. Gastroenterology 144:1220-1229. https://doi.org/10.1053/j.gastro.2013.01.071

66. Deramaudt T, Rustgi AK (2005) Mutant KRAS in the initiation of pancreatic cancer. Biochim Biophys Acta Rev Cancer 1756:97-101. https://doi.org/10.1016/j.bbcan.2005.08.003

67. Saqui-Salces M, Keeley TM, Grosse AS et al (2011) Gastric tuft cells express DCLK1 and are expanded in hyperplasia. Histochem Cell Biol 136:191-204. https://doi.org/10.1007/s0041 8-011-0831-1

68. Perera RM, Bardeesy N (2012) Ready, set, go: the EGF receptor at the pancreatic cancer starting line. Cancer Cell 22:281-282. https://doi.org/10.1016/j.ccr.2012.08.019

69. Cho WCS, Chow ASC, Au JSK (2011) MiR-145 inhibits cell proliferation of human lung adenocarcinoma by targeting EGFR and NUDT1. RNA Biol 8:125-131

70. Zhu H, Dougherty U, Robinson V et al (2011) EGFR signals downregulate tumor suppressors miR-143 and miR-145 in western diet-promoted murine colon cancer: role of G1 regulators. Mol Cancer Res 9:960-975. https://doi.org/10.1158/1541-7786. MCR-10-0531

71. Brabletz S, Bajdak K, Meidhof S et al (2011) The ZEB1/miR-200 feedback loop controls Notch signalling in cancer cells. EMBO J 30:770-782. https://doi.org/10.1038/emboj.2010.349

72. Akao Y, Nakagawa Y, Kitade Y et al (2007) Downregulation of microRNAs-143 and -145 in B-cell malignancies. Cancer Sci 98:1914-1920. https://doi.org/10.1111/j.1349-7006.2007.00618 .X

73. Han J, Wang L, Wang X, Li K (2016) Downregulation of microrna-126 contributes to tumorigenesis of squamous tongue cell carcinoma via targeting KRAS. Med Sci Monit 22:522-529. https://doi.org/10.12659/MSM.895306

74. Subramanian RR, Masters SC, Zhang H, Fu H (2001) Functional conservation of 14-3-3 isoforms in inhibiting bad-induced 
apoptosis. Exp Cell Res 271:142-151. https://doi.org/10.1006/ excr.2001.5376

75. Samuel T, Weber HO, Rauch $P$ et al (2001) The $G_{2} / M$ regulator 14-3-3 $\varsigma$ prevents apoptosis through sequestration of Bax. J Biol Chem 276:45201-45206. https://doi.org/10.1074/jbc.M1064 27200

76. Korc M (2003) Pathways for aberrant angiogenesis in pancreatic cancer. Mol Cancer 2:8. https://doi.org/10.1186/1476-4598-2-8

77. Ogawa T, Takayama K, Takakura N et al (2002) Anti-tumor angiogenesis therapy using soluble receptors: enhanced inhibition of tumor growth when soluble fibroblast growth factor receptor-1 is used with soluble vascular endothelial growth factor receptor. Cancer Gene Ther 9:633-640. https://doi.org/10.1038/ sj.cgt. 7700478

78. Solorzano CC, Baker CH, Bruns CJ et al (2001) Inhibition of growth and metastasis of human pancreatic cancer growing in nude mice by PTK 787/ZK222584, an inhibitor of the vascular endothelial growth factor receptor tyrosine kinases. Cancer Biother Radiopharm 16:359-370. https://doi.org/10.1089/10849 7801753354267

79. Hoshida T, Sunamura M, Duda DG et al (2002) Gene therapy for pancreatic cancer using an adenovirus vector encoding soluble flt-1 vascular endothelial growth factor receptor. Pancreas 25:111-121

80. Roybal JD, Zang Y, Ahn Y-H et al (2011) miR-200 inhibits lung adenocarcinoma cell invasion and metastasis by targeting Flt1/VEGFR1. Mol Cancer Res 9:25-35. https://doi. org/10.1158/1541-7786.MCR-10-0497

81. Choi Y-C, Yoon S, Jeong Y et al (2011) Regulation of vascular endothelial growth factor signaling by miR-200b. Mol Cells 32:77-82. https://doi.org/10.1007/s10059-011-1042-2

82. Nishio K, Kimura K, Amano R et al (2017) Doublecortin and CaM kinase-like-1 as an independent prognostic factor in patients with resected pancreatic carcinoma. World J Gastroenterol 23:5764-5772. https://doi.org/10.3748/wjg.v23.i31.5764

83. Ito H, Tanaka S, Akiyama Y et al (2016) Dominant expression of DCLK1 in human pancreatic cancer stem cells accelerates tumor invasion and metastasis. PLoS ONE 11:e0146564. https://doi. org/10.1371/journal.pone.0146564

84. Xia H, Ng SS, Jiang S et al (2010) miR-200a-mediated downregulation of ZEB2 and CTNNB1 differentially inhibits nasopharyngeal carcinoma cell growth, migration and invasion. Biochem Biophys Res Commun 391:535-541. https://doi.org/10.1016/j. bbrc.2009.11.093

85. Korpal M, Lee ES, Hu G, Kang Y (2008) The miR-200 family inhibits epithelial-mesenchymal transition and cancer cell migration by direct targeting of E-cadherin transcriptional repressors ZEB1 and ZEB2. J Biol Chem 283:14910-14914. https://doi. org/10.1074/jbc.C800074200

86. Li J, Wang Y, Ge J et al (2018) Doublecortin-like kinase 1 (DCLK1) regulates B cell-specific moloney murine leukemia virus insertion site 1 (Bmi-1) and is associated with metastasis and prognosis in pancreatic cancer. Cell Physiol Biochem 51:262-277. https://doi.org/10.1159/000495228

87. Chen C, Zhao S, Karnad A, Freeman JW (2018) The biology and role of CD44 in cancer progression: therapeutic implications. J Hematol Oncol 11(1):64

88. Sneath RJS, Mangham DC (1998) The normal structure and function of CD44 and its role in neoplasia. J Clin Pathol Mol Pathol 51(4):191

89. Li Z, Chen K, Jiang P et al (2014) CD44v/CD44 s expression patterns are associated with the survival of pancreatic carcinoma patients. Diagn Pathol 9:79. https://doi. org/10.1186/1746-1596-9-79

90. Godar S, Ince TA, Bell GW et al (2008) Growth-inhibitory and tumor-suppressive functions of p53 depend on its repression of
CD44 expression. Cell 134:62-73. https://doi.org/10.1016/j. cell.2008.06.006

91. Orian-Rousseau V (2002) CD44 is required for two consecutive steps in HGF/c-Met signaling. Genes Dev 16:3074-3086. https ://doi.org/10.1101/gad.242602

92. Mielgo A, van Driel M, Bloem A et al (2006) A novel antiapoptotic mechanism based on interference of Fas signaling by CD44 variant isoforms. Cell Death Differ. https://doi.org/10.1038/ sj.cdd. 4401763

93. Bourguignon LYW, Wong G, Earle C, Chen L (2012) Hyaluronan-CD44v3 interaction with Oct4-Sox2-Nanog promotes miR-302 expression leading to self-renewal, clonal formation, and cisplatin resistance in cancer stem cells from head and neck squamous cell carcinoma. J Biol Chem. https://doi.org/10.1074/ jbc.M111.308528

94. Bourguignon LYW, Earle C, Wong G et al (2012) Stem cell marker (Nanog) and Stat-3 signaling promote microRNA-21 expression and chemoresistance in hyaluronan/CD44-activated head and neck squamous cell carcinoma cells. Oncogene 31:149160. https://doi.org/10.1038/onc.2011.222

95. Bourguignon LYW, Spevak CC, Wong G et al (2009) Hyaluronan-CD44 interaction with protein kinase Ce promotes oncogenic signaling by the stem cell marker Nanog and the production of microRNA-21, leading to down-regulation of the tumor suppressor protein PDCD4, anti-apoptosis, and chemotherapy resistance in breast tumor cells. J Biol Chem 284:26533-26546. https://doi.org/10.1074/jbc.M109.027466

96. Shiina M, Bourguignon LYW (2015) Selective activation of cancer stem cells by size-specific hyaluronan in head and neck cancer. Int J Cell Biol. https://doi.org/10.1155/2015/989070

97. Cho SH, Park YS, Kim HJ et al (2012) CD44 enhances the epithelial-mesenchymal transition in association with colon cancer invasion. Int J Oncol. https://doi.org/10.3892/ijo.2012.1453

98. Ponta H, Sherman L, Herrlich PA (2003) CD44: from adhesion molecules to signalling regulators. Nat Rev Mol Cell Biol 4(1):33

99. Yae T, Tsuchihashi K, Ishimoto T et al (2012) Alternative splicing of CD44 mRNA by ESRP1 enhances lung colonization of metastatic cancer cell. Nat Commun. https://doi.org/10.1038/ ncomms 1892

100. Brown RL, Reinke LM, Damerow MS et al (2011) CD44 splice isoform switching in human and mouse epithelium is essential for epithelial-mesenchymal transition and breast cancer progression. J Clin Invest. https://doi.org/10.1172/JCI44540

101. Li X-P, Zhang X-W, Zheng L-Z, Guo W-J (2015) Expression of CD44 in pancreatic cancer and its significance. Int J Clin Exp Pathol 8:6724-6731

102. Hong SP, Wen J, Bang S et al (2009) CD44-positive cells are responsible for gemcitabine resistance in pancreatic cancer cells. Int J Cancer 125:2323-2331. https://doi.org/10.1002/ijc.24573

103. Kayali AG, Van Gunst K, Campbell IL et al (2003) The stromal cell-derived factor-1alpha/CXCR104 ligand-receptor axis is critical for progenitor survival and migration in the pancreas. J Cell Biol 163:859-869. https://doi.org/10.1083/jcb.200304153

104. Lataillade J-J, Domenech J, Le Bousse-Kerdilès M-C (2004) Stromal cell-derived factor-1 (SDF-1)\CXCR105 couple plays multiple roles on haematopoietic progenitors at the border between the old cytokine and new chemokine worlds: survival, cell cycling and trafficking. Eur Cytokine Netw 15:177-188

105. Koshiba T, Hosotani R, Miyamoto Y et al (2000) Expression of stromal cell-derived factor 1 and CXCR106 ligand receptor system in pancreatic cancer: a possible role for tumor progression. Clin Cancer Res 6:3530-3535

106. Gao Z, Wang X, Wu K et al (2010) Pancreatic stellate cells increase the invasion of human pancreatic cancer cells through the stromal cell-derived factor-1/CXCR107 axis. Pancreatology 10:186-193. https://doi.org/10.1159/000236012 
107. Marchesi F, Monti P, Leone BE et al (2004) Increased survival, proliferation, and migration in metastatic human pancreatic tumor cells expressing functional CXCR108. Cancer Res 64:8420-8427. https://doi.org/10.1158/0008-5472.CAN-04-1343

108. Pozzobon T, Goldoni G, Viola A, Molon B (2016) CXCR109 signaling in health and disease. Immunol Lett 177:6-15. https:// doi.org/10.1016/j.imlet.2016.06.006

109. Rath D, Chatterjee M, Meyer L et al (2018) Relative survival potential of platelets is associated with platelet CXCR110/ CXCR110 surface exposure and functional recovery following STEMI. Atherosclerosis 278:269-277. https://doi.org/10.1016/j. atherosclerosis.2018.10.008

110. Spencer A, Jackson J, Baulch-Brown C (2001) Enumeration of bone marrow "homing" haemopoietic stem cells from G-CSFmobilised normal donors and influence on engraftment following allogeneic transplantation. Bone Marrow Transplant 28:10191022. https://doi.org/10.1038/sj.bmt.1703289

111. Wright DE, Bowman EP, Wagers AJ et al (2002) Hematopoietic stem cells are uniquely selective in their migratory response to chemokines. J Exp Med 195:1145-1154. https://doi.org/10.1084/ jem.20011284

112. Vandercappellen J, Van Damme J, Struyf S (2008) The role of CXC chemokines and their receptors in cancer. Cancer Lett 267:226-244. https://doi.org/10.1016/j.canlet.2008.04.050

113. Kucia M, Reca R, Miekus K et al (2005) Trafficking of normal stem cells and metastasis of cancer stem cells involve similar mechanisms: pivotal role of the SDF-1-CXCR114 axis. Stem Cells 23:879-894. https://doi.org/10.1634/stemcells.2004-0342

114. Burger JA, Kipps TJ (2006) CXCR115: a key receptor in the crosstalk between tumor cells and their microenvironment. Blood 107:1761-1767. https://doi.org/10.1182/blood-2005-08-3182

115. Maréchal R, Demetter P, Nagy N et al (2009) High expression of CXCR116 may predict poor survival in resected pancreatic adenocarcinoma. Br J Cancer 100:1444-1451. https://doi. org/10.1038/sj.bjc.6605020

116. Cui K, Zhao W, Wang C et al (2011) The CXCR117-CXCL12 pathway facilitates the progression of pancreatic cancer via induction of angiogenesis and lymphangiogenesis. J Surg Res 171:143-150. https://doi.org/10.1016/j.jss.2010.03.001

117. Takeda J, Seino S, Bell GI (1992) Human Oct3 gene family: cDNA sequences, alternative splicing, gene organization, chromosomal location, and expression at low levels in adult tissues. Nucleic Acids Res 20:4613-4620

118. Zaehres H, Lensch MW, Daheron L et al (2005) High-efficiency RNA interference in human embryonic stem cells. Stem Cells 23:299-305. https://doi.org/10.1634/stemcells.2004-0252

119. Radzisheuskaya A, Silva JCR (2014) Do all roads lead to Oct4? The emerging concepts of induced pluripotency. Trends Cell Biol 24:275-284. https://doi.org/10.1016/j.tcb.2013.11.010

120. Wu G, Schöler HR (2014) Role of Oct4 in the early embryo development. Cell Regen (London, England) 3:7. https://doi. org/10.1186/2045-9769-3-7

121. Zeineddine D, Hammoud AA, Mortada M, Boeuf H (2014) The Oct4 protein: more than a magic stemness marker. Am J Stem Cells 3:74-82

122. Villodre ES, Kipper FC, Pereira MB, Lenz G (2016) Roles of OCT4 in tumorigenesis, cancer therapy resistance and prognosis. Cancer Treat Rev 51:1-9. https://doi.org/10.1016/j. ctrv.2016.10.003

123. Boer B, Kopp J, Mallanna S et al (2007) Elevating the levels of Sox 2 in embryonal carcinoma cells and embryonic stem cells inhibits the expression of Sox2:Oct-3/4 target genes. Nucleic Acids Res 35:1773-1786. https://doi.org/10.1093/nar/gkm059
124. Wen J, Park JY, Park KH, Chung HW, Bang S, Park SW, Song SY (2010) Oct4 and Nanog expression is associated with early stages of pancreatic carcinogenesis. Pancreas 39(5):622-626

125. Lin H, Sun L-H, Han W et al (2014) Knockdown of OCT4 suppresses the growth and invasion of pancreatic cancer cells through inhibition of the AKT pathway. Mol Med Rep 10:13351342. https://doi.org/10.3892/mmr.2014.2367

126. Lu Y, Zhu H, Shan H et al (2013) Knockdown of Oct4 and Nanog expression inhibits the stemness of pancreatic cancer cells. Cancer Lett 340:113-123. https://doi.org/10.1016/j.canle t.2013.07.009

127. Maetzel D, Denzel S, Mack B et al (2009) Nuclear signalling by tumour-associated antigen EpCAM. Nat Cell Biol. https://doi. org/10.1038/ncb1824

128. Wang MH, Sun R, Zhou XM et al (2018) Epithelial cell adhesion molecule overexpression regulates epithelial-mesenchymal transition, stemness and metastasis of nasopharyngeal carcinoma cells via the PTEN/AKT/mTOR pathway. Cell Death Dis. https ://doi.org/10.1038/s41419-017-0013-8

129. Fong D, Steurer M, Obrist P et al (2008) Ep-CAM expression in pancreatic and ampullary carcinomas: frequency and prognostic relevance. J Clin Pathol 61:31-35. https://doi.org/10.1136/ jcp.2006.037333

130. Ambudkar SV, Kimchi-Sarfaty C, Sauna ZE, Gottesman MM (2003) P-glycoprotein: from genomics to mechanism. Oncogene 22:7468-7485. https://doi.org/10.1038/sj.onc.1206948

131. Harpstrite SE, Gu H, Natarajan R, Sharma V (2014) Interrogation of multidrug resistance (MDR1) P-glycoprotein (ABCB1) expression in human pancreatic carcinoma cells. Nucl Med Commun 35:1067-1070. https://doi.org/10.1097/MNM.0000000000 000158

132. Katoh M (2018) Multi-layered prevention and treatment of chronic inflammation, organ fibrosis and cancer associated with canonical WNT/ $\beta$-catenin signaling activation (review). Int J Mol Med 42:713-725. https://doi.org/10.3892/ijmm.2018.3689

133. Harbuzariu A, Rampoldi A, Daley-Brown DS et al (2017) LeptinNotch signaling axis is involved in pancreatic cancer progression. Oncotarget 8:7740-7752. https://doi.org/10.18632/oncotarget .13946

134. Bloomston M, Frankel WL, Petrocca F et al (2007) MicroRNA expression patterns to differentiate pancreatic adenocarcinoma from normal pancreas and chronic pancreatitis. JAMA 297:1901. https://doi.org/10.1001/jama.297.17.1901

135. Moriyama T, Ohuchida K, Mizumoto K et al (2009) MicroRNA-21 modulates biological functions of pancreatic cancer cells including their proliferation, invasion, and chemoresistance. Mol Cancer Ther 8:1067-1074. https://doi.org/10.1158/15357163.MCT-08-0592

136. Hwang J-H, Voortman J, Giovannetti E et al (2010) Identification of microRNA-21 as a biomarker for chemoresistance and clinical outcome following adjuvant therapy in resectable pancreatic cancer. PLoS ONE 5:e10630. https://doi.org/10.1371/journ al.pone. 0010630

137. Callaghan R, Luk F, Bebawy M (2014) Inhibition of the multidrug resistance P-glycoprotein: time for a change of strategy? Drug Metab Dispos 42:623-631. https://doi.org/10.1124/ dmd.113.056176

138. Lu Z, Kleeff J, Shrikhande S et al (2000) Expression of the multidrug-resistance 1 (MDR1) gene and prognosis in human pancreatic cancer. Pancreas 21:240-247

139. Wei HJ, Yin T, Zhu Z et al (2011) Expression of CD44, CD24 and ESA in pancreatic adenocarcinoma cell lines varies with local microenvironment. Hepatobiliary Pancreat Dis Int 10:428434. https://doi.org/10.1016/S1499-3872(11)60073-8 
140. Li C, Heidt DG, Dalerba P et al (2007) Identification of pancreatic cancer stem cells. Am Assoc Cancer Res J 67:1030-1038. https://doi.org/10.1158/0008-5472.CAN-06-2030

141. Chen JK, Taipale J, Young KE et al (2002) Small molecule modulation of smoothened activity. Proc Natl Acad Sci USA 99:14071-14076. https://doi.org/10.1073/pnas.182542899

142. Skoda J, Hermanova M, Loja T et al (2016) Co-expression of cancer stem cell markers corresponds to a pro-tumorigenic expression profile in pancreatic adenocarcinoma. PLoS ONE 11:159255. https://doi.org/10.1371/journal.pone.0159255

143. Li Y, Kong D, Ahmad A et al (2013) Pancreatic cancer stem cells: emerging target for designing novel therapy. Cancer Lett 338:94-100. https://doi.org/10.1016/j.canlet.2012.03.018

144. Zhao S, Chen C, Chang K et al (2016) CD44 expression level and isoform contributes to pancreatic cancer cell plasticity, invasiveness, and response to therapy. Clin Cancer Res 22:5592-5604. https://doi.org/10.1158/1078-0432.CCR-15-3115

145. Dean M, Fojo T, Bates S (2005) Tumour stem cells and drug resistance. Nat Rev Cancer 5:275-284. https://doi.org/10.1038/ $\operatorname{nrc} 1590$

146. Pang L, Word B, Xu J et al (2014) ATP-binding cassette genes genotype and expression: a potential association with pancreatic cancer development and chemoresistance? Gastroenterol Res Pract 2014:1-9. https://doi.org/10.1155/2014/414931

147. Miletti-González KE, Chen S, Muthukumaran N et al (2005) The CD44 receptor interacts with P-glycoprotein to promote cell migration and invasion in cancer. Cancer Res 65:6660-6667. https://doi.org/10.1158/0008-5472.CAN-04-3478

148. Bourguignon LYW, Peyrollier K, Xia W, Gilad E (2008) Hyaluronan-CD44 interaction activates stem cell marker Nanog, Stat-3-mediated MDR1 gene expression, and ankyrin-regulated multidrug efflux in breast and ovarian tumor cells. J Biol Chem 283:17635-17651. https://doi.org/10.1074/jbc.M800109200

149. Kiuchi S, Ikeshita S, Miyatake Y, Kasahara M (2015) Pancreatic cancer cells express CD44 variant 9 and multidrug resistance protein 1 during mitosis. Exp Mol Pathol 98:41-46. https://doi. org/10.1016/j.yexmp.2014.12.001

150. Li L, Hao X, Qin J et al (2014) Antibody against CD44 s inhibits pancreatic tumor initiation and postradiation recurrence in mice. Gastroenterology 146:1108-1118. https://doi.org/10.1053/j.gastr o.2013.12.035

151. Rauchwerger DR, Firby PS, Hedley DW, Moore MJ (2000) Equilibrative-sensitive nucleoside transporter and its role in gemcitabine sensitivity. Cancer Res 60:6075-6079

152. Duxbury MS, Ito H, Zinner MJ et al (2004) Inhibition of SRC tyrosine kinase impairs inherent and acquired gemcitabine resistance in human pancreatic adenocarcinoma cells. Clin Cancer Res 10:2307-2318

153. Shi X, Liu S, Kleeff J et al (2002) Acquired resistance of pancreatic cancer cells towards 5-fluorouracil and gemcitabine is associated with altered expression of apoptosis-regulating genes. Oncology 62:354-362. https://doi.org/10.1159/000065068

154. Galmarini CM, Clarke ML, Falette N et al (2002) Expression of a non-functional p53 affects the sensitivity of cancer cells to gemcitabine. Int J Cancer 97:439-445

155. Goan YG, Zhou B, Hu E et al (1999) Overexpression of ribonucleotide reductase as a mechanism of resistance to 2,2-difluorodeoxycytidine in the human KB cancer cell line. Cancer Res 59:4204-4207

156. Ioannou N, Seddon AM, Dalgleish A et al (2016) Acquired resistance of pancreatic cancer cells to treatment with gemcitabine and HER-inhibitors is accompanied by increased sensitivity to STAT3 inhibition. Int J Oncol 48:908-918. https://doi. org/10.3892/ijo.2016.3320
157. Chio IIC, Jafarnejad SM, Ponz-Sarvise M et al (2016) NRF2 promotes tumor maintenance by modulating mRNA translation in pancreatic cancer. Cell 166:963-976. https://doi.org/10.1016/j. cell.2016.06.056

158. Chen S-H, Li D-L, Yang F et al (2014) Gemcitabine-induced pancreatic cancer cell death is associated with MST1/cyclophilin D mitochondrial complexation. Biochimie 103:71-79. https:// doi.org/10.1016/j.biochi.2014.04.004

159. Song Y, Baba T, Li Y-Y et al (2015) Gemcitabine-induced CXCL8 expression counteracts its actions by inducing tumor neovascularization. Biochem Biophys Res Commun 458:341346. https://doi.org/10.1016/j.bbrc.2015.01.112

160. Copple IM, Goldring CE, Kitteringham NR, Park BK (2010) The Keap1-Nrf2 cellular defense pathway: mechanisms of regulation and role in protection against drug-induced toxicity. Handbook of experimental pharmacology. Springer, Berlin, pp 233-266

161. Alam J, Stewart D, Touchard C et al (1999) Nrf2, a Cap'n'Collar transcription factor, regulates induction of the heme oxygenase-1 gene. J Biol Chem 274:26071-26078. https://doi.org/10.1074/ jbc.274.37.26071

162. Du Z, Qin R, Wei C et al (2011) Pancreatic cancer cells resistant to chemoradiotherapy rich in "stem-cell-like" tumor cells. Dig Dis Sci 56:741-750. https://doi.org/10.1007/s10620-010-1340-0

163. Lee CJ, Dosch J, Simeone DM (2015) Pancreatic cancer stem cells. J Clin Oncol. https://doi.org/10.1200/JCO.2008.16.6702

164. Shah AN, Summy JM, Zhang J et al (2007) Development and characterization of gemcitabine-resistant pancreatic tumor cells. Ann Surg Oncol 14:3629-3637. https://doi.org/10.1245/s1043 4-007-9583-5

165. Cho JH, Kim SA, Park SB et al (2017) Suppression of pancreatic adenocarcinoma upregulated factor (PAUF) increases the sensitivity of pancreatic cancer to gemcitabine and 5FU, and inhibits the formation of pancreatic cancer stem like cells. Oncotarget 8:76398-76407. https://doi.org/10.18632/oncotarget.19458

166. Wang D, Zhu H, Zhu Y et al (2013) Retracted: CD133+/CD44+/ Oct4+/Nestin + stem-like cells isolated from Panc-1 cell line may contribute to multi-resistance and metastasis of pancreatic cancer. Acta Histochem 115:349-356. https://doi.org/10.1016/j.acthi s.2012.09.007

167. Zhao H, Duan Q, Zhang Z et al (2017) Up-regulation of glycolysis promotes the stemness and EMT phenotypes in gemcitabineresistant pancreatic cancer cells. J Cell Mol Med 21:2055-2067. https://doi.org/10.1111/jcmm.13126

168. Javed MA, Beyer G, Le N et al (2018) Impact of intensified chemotherapy in metastatic pancreatic ductal adenocarcinoma (PDAC) in clinical routine in Europe. Pancreatology. https://doi. org/10.1016/j.pan.2018.10.003

169. Conroy T, Hammel P, Hebbar M et al (2018) FOLFIRINOX or gemcitabine as adjuvant therapy for pancreatic cancer. N Engl J Med 379:2395-2406. https://doi.org/10.1056/NEJMoa1809775

170. Mueller MT, Hermann PC, Witthauer J et al (2009) Combined targeted treatment to eliminate tumorigenic cancer stem cells in human pancreatic cancer. Gastroenterology 137:1102-1113. https://doi.org/10.1053/j.gastro.2009.05.053

171. Mohammed A, Janakiram NB, Brewer M et al (2013) Antidiabetic drug metformin prevents progression of pancreatic cancer by targeting in part cancer stem cells and mTOR signaling. Transl Oncol 6:649-659

172. Zhang Y, Guan M, Zheng Z et al (2013) Effects of metformin on CD133+ colorectal cancer cells in diabetic patients. PLoS ONE 8:e81264. https://doi.org/10.1371/journal.pone.0081264

173. Gupta VK, Sharma NS, Kesh K et al (2018) Metastasis and chemoresistance in CD133 expressing pancreatic cancer cells are dependent on their lipid raft integrity. Cancer Lett 439:101-112. https://doi.org/10.1016/j.canlet.2018.09.028 
174. Rangarajan P, Subramaniam D, Paul S et al (2015) Crocetinic acid inhibits hedgehog signaling to inhibit pancreatic cancer stem cells. Oncotarget 6:27661-27673. https://doi.org/10.18632/oncot arget.4871

175. Sureban SM, May R, Weygant N et al (2014) XMD8-92 inhibits pancreatic tumor xenograft growth via a DCLK1-dependent mechanism. Cancer Lett 351:151-161. https://doi.org/10.1016/j. canlet.2014.05.011

176. Kawamura D, Takemoto Y, Nishimoto A et al (2017) Enhancement of cytotoxic effects of gemcitabine by Dclk1 inhibition through suppression of Chk1 phosphorylation in human pancreatic cancer cells. Oncol Rep 38:3238-3244. https://doi. org/10.3892/or.2017.5974

177. Park B, Sung B, Yadav VR et al (2011) Acetyl-11-keto- $\beta$ boswellic acid suppresses invasion of pancreatic cancer cells through the downregulation of CXCR183 chemokine receptor expression. Int J Cancer 129:23-33. https://doi.org/10.1002/ ijc. 25966

178. Wang Z, Ma Q, Liu Q et al (2008) Blockade of SDF-1/CXCR184 signalling inhibits pancreatic cancer progression in vitro via inactivation of canonical Wnt pathway. Br J Cancer 99:1695-1703. https://doi.org/10.1038/sj.bjc.6604745

179. Gao L, Yang Y, Xu H, Liu R, Li D, Hong H, Qin M, Wang Y (2014) MiR-335 functions as a tumor suppressor in pancreatic cancer by targeting OCT4. Tumor Biol 35(8):8309-8318

Publisher's Note Springer Nature remains neutral with regard to jurisdictional claims in published maps and institutional affiliations. 